\title{
Incidencia de la política criminal en la seguridad. Especial referencia a la delincuencia organizada y transnacional
}

\author{
María Gavilán Rubio
}

Recibido: 14/12/2020 / Aceptado: 08/07/2021

Resumen. En el presente artículo vamos a analizar como la delincuencia organizada y transnacional, que supone un flagrante ataque a los derechos humanos y la ruptura del orden público y la paz social, forman parte de los Objetivos de Desarrollo Sostenible y ponen de manifiesto que para su erradicación se hacen necesarias políticas criminales adecuadas, políticas criminales modernas y multidisciplinares, transversales que no centren su atención únicamente en el ámbito punitivo y retributivo del derecho penal, si no que se sirvan de otras disciplinas como la sociología, respetando el principio de intervención mínima que ha de caracterizar al derecho penal.

Así mismo hemos visto la interrelación e impacto que tiene esta cuestión en la seguridad ciudadana, partiendo la política criminal en España y en concreto en el ámbito de la seguridad ciudadana y el orden público, teniendo en cuenta cuestiones como el factor territorial del delito.

Por último, hemos propuesto como abordar la política criminal en la delincuencia organizada y trasnacional con especial referencia al delito de trata de seres humanos.

Palabras claves: Política criminal, objetivos de desarrollo sostenible, ODS, derecho penal, principio de intervención mínima, delincuencia organizada y trasnacional, trata de seres humanos, seguridad ciudadana.

\section{[en] The impact of criminal policy on security. Special reference to organised and transnational crime}

Summary. In this article we are going to analyse how organised and transnational crime, which is a flagrant attack on human rights and the breakdown of public order and social peace, forms part of the Sustainable Development Goals and shows that in order to eradicate it, adequate criminal policies are needed, modern and multidisciplinary criminal policies that do not focus their attention solely on the punitive and retributive sphere of criminal law, but that make use of other disciplines such as sociology, respecting the principle of minimum intervention that must characterise criminal law.

We have also looked at the interrelationship and impact of this issue on public safety, starting with criminal policy in Spain and specifically in the field of public safety and public order, taking into account issues such as the territorial factor of crime.

Finally, we have proposed how to approach criminal policy in organised and transnational crime with special reference to the crime of trafficking in human beings.

Keywords: Criminal policy, sustainable development goals, SDGs, criminal law, principle of minimum intervention, organised and transnational crime, human trafficking, citizen security.

Sumario. 1. Introducción. 2. Seguridad ciudadana y objetivos de desarrollo sostenible. 2.1. ODS número 5: Igualdad de género. 2.2. ODS número 16: Paz, justicia e instituciones sólidas. 3. Política Criminal y Seguridad. 3.1. La política criminal en España. 3.2. La política criminal en el ámbito de la seguridad ciudadana y el orden público. 3.3. La relevancia del factor territorial del delito. 4. Delincuencia organizada y trasnacional y seguridad. Política Criminal. Conclusiones. Abreviaturas. Bibliografía.

Cómo citar: Gavilán Rubio, M. (2021): Incidencia de la política criminal en la seguridad. Especial referencia a la delincuencia organizada y transnacional, en Cuadernos de Gobierno y Administración Pública 8-1, 83-90.

\section{Introducción}

Los Objetivos de Desarrollo Sostenible determinan las líneas de actuación y las políticas públicas de los gobiernos, creando un marco para las mismas, lo que sucede específicamente en el ámbito de las políticas públicas de seguridad.

La delincuencia organizada y transnacional supone un flagrante ataque a los derechos humanos y la ruptura del orden público y la paz social, por lo que se hacen ne- 
cesarias políticas criminales adecuadas que contribuyan a erradicar este fragelo que supone el terrorismo, la trata de personas, la corrupción, o el tráfico de drogas o armas.

Destacamos a este respecto la especial incidencia de los Objetivos de Desarrollo Sostenible 5 y 16, sin perjuicio de la necesaria coadyuvación del resto.

Se hacen necesarias políticas criminales modernas que no centren su atención en el ámbito punitivo y retributivo del derecho penal, si no que se sirvan de otras disciplinas como la sociología, y un ámbito penal que incluya una visión global que parta del principio de intervención mínima, y no pierda el sentido de una adecuada ejecución de penas que consiga el fin constitucionalmente previsto, que es la reinserción social. Políticas criminales que pongan su énfasis en la prevención e involucren a la ciudadanía en una cultura de legalidad propia de avanzados estados de derecho. Esta política criminal tiene que tener un enfoque territorial que permita un mejor conocimiento del fenómeno delictivo y facilite su prevención a través de la proximidad.

Proponemos el abordaje de políticas criminales modernas en la lucha contra la delincuencia organizada y transnacional, con énfasis en la prevención, persecución del delito a través de la coordinación interinstitucional y la cooperación internacional, y la protección de las víctimas tratando de dotar de un enfoque victimocéntrico al proceso penal.

\section{Seguridad ciudadana y Objetivos De Desarrollo Sostenible}

El 25 de septiembre de 2015, los líderes mundiales adoptaron un conjunto de objetivos globales (objetivos de desarrollo sostenible, en lo sucesivo ODS) en el seno de Naciones Unidas, confeccionando una nueva agenda para el desarrollo sostenible, la denominada agenda 2030. Cada uno de estos objetivos contiene metas específicas, y su consecución se planea en 15 años ${ }^{2}$.

De estos objetivos hay dos que inciden de manera sustancial en la seguridad ciudadana: el objetivo 5 relativo a la igualdad de género y el objetivo 16, sobre paz, justicia e instituciones sólidas, sin perjuicio de que todos ellos coadyuvan de forma indirecta a su consecución.

\subsection{ODS número 5: igualdad de género}

Según Naciones Unidas, las leyes y las normas sociales discriminatorias continúan siendo generalizadas, las mujeres continuamos estando infrarrepresentadas a todos los niveles de liderazgo político, y con especial incidencia en lo que a la seguridad ciudadana se refiere, un dato espeluznante: 1 de cada 5 mujeres y niñas de entre 15 y 49 años afirma haber sufrido violencia sexual o física a manos de una pareja íntima en un período de 12 meses.

Este objetivo incide en la seguridad ciudadana porque no podemos obviar los datos que Naciones Unidas nos proporciona al respecto: A nivel mundial, 750 millones

En: https://www.un.org/sustainabledevelopment/es/objetivos-de-desarrollo-sostenible/ de mujeres y niñas se casaron antes de los 18 años y al menos 200 millones de mujeres y niñas en 30 países se sometieron a la mutilación genital femenina (MGF). En 18 países, en el caso de mujeres casadas, sus maridos pueden impedir legalmente que trabajen; en 39 países, las hijas y los hijos no tienen los mismos derechos de herencia; y en 49 países no existen leyes que protejan a las mujeres de la violencia doméstica. Una de cada cinco mujeres y niñas, incluido el $19 \%$ de las mujeres y las niñas de 15 a 49 años, han sufrido violencia física y/o sexual por parte de una pareja íntima, durante los últimos 12 meses. Sin embargo, en 49 países no existen leyes que protejan específicamente a las mujeres contra tal violencia. Datos que objetivizan y reflejan como la violencia nos afecta de forma desproporcionada a las mujeres.

Los efectos derivados de la crisis sanitaria derivada de la COVID 19 que estamos viviendo podría revertir los escasos logros que se han alcanzado en materia de igualdad de género y derechos de las mujeres y niñas, pues la pandemia agrava las desigualdades existentes a nivel mundial, lo que tiene incidencia obviamente en la salud y en la economía, pero también en otras esferas como la seguridad ciudadana.

La pandemia también ha supuesto un fuerte aumento de la violencia contra las mujeres y niñas, y las medidas de confinamiento ha incrementado la violencia de género intrafamiliar, habiéndose encontrado muchas mujeres, en situación de confinamiento, con dificultades para acceder a servicios que además están padeciendo recortes y restricciones en muchos países ${ }^{3}$.

Entre las metas de este objetivo se encuentra eliminar todas las formas de violencia contra todas las mujeres y niñas en los ámbitos públicos y privado, incluidas la trata y explotación sexual, y otros tipos de explotación, delincuencias cometidas a menudo a través de delincuencia organizada y trasnacional. Pretende también eliminar prácticas como el matrimonio infantil y la MGF. Para estos objetivos que tienen incidencia en la seguridad hay que poner fin a todas las formas de discriminación de las mujeres y niñas, asegurar la participación plena y efectiva de las mujeres en todos los ámbitos garantizando la igualdad de oportunidades para mujeres y niñas, así como la oportunidad de liderazgo a todos los niveles, y en especial en la vida política, económica y pública.

\subsection{ODS número 6: Paz, justicia e instituciones sólidas}

El desarrollo sostenible se encuentra gravemente amenazado por los conflictos, la inseguridad, instituciones débiles y el acceso limitado a la justicia.

El número de personas que huyen de las guerras, las persecuciones y los conflictos superó los 70 millones en 2018, la cifra más alta registrada por la Oficina del Alto Comisionado de las Naciones Unidas para los Refugiados (ACNUR) en casi 70 años.

En el centro de todos los debates debe haber un mínimo infranqueable e incuestionable: los derechos huma-

En: https://www.un.org/sites/un2.un.org/files/policy_brief_on_covid_ impact_on_women_9_april_2020.pdf 
nos; las personas y sus derechos como centro del debate. Y todas las respuestas desde los poderes públicos a todas las situaciones, y más a situaciones como la actual crisis sanitaria, deben proteger los derechos humanos y el estado de derecho.

Señala Naciones Unidas que entre las instituciones más afectadas por la corrupción se encuentran el poder judicial y la policía, de indudable trascendencia en la seguridad pública, de ahí la importancia de la necesidad de instituciones sólidas.

Entre las metas de este objetivo se encuentra reducir significativamente todas las formas de violencia, y poner fin al maltrato, la explotación, la trata y todas las formas de violencia y tortura, promoviendo el estado de derecho y garantizando el acceso a la justicia y la igualdad, creando instituciones eficaces y transparentes. Debemos ser capaces de prevenir la violencia y combatir el terrorismo y la delincuencia, promover y aplicar leyes y políticas no discriminatorias y en favor de ese desarrollo sostenible ${ }^{4}$.

Necesitamos implementar políticas integrales, y en lo que al ámbito delictual se refiere, necesitamos adecuadas políticas criminales, con énfasis en la prevención, y con enfoque territorial, lo cual supondría obviamente un impacto en la construcción de sociedades pacíficas e inclusivas, buscando reducir todas las formas de violencia. Debemos romper los ciclos de exclusión y violencia, en favor de establecer como contrapartida sinergias positivas de paz y desarrollo, desarrollando sistemas de alerta temprana, necesitando por tanto infraestructuras de paz, para lo que es absolutamente imprescindible el abordaje desde enfoques territoriales, promoviendo la cohesión social y la participación inclusiva en la sociedad.

Fortalecer el Estado de Derecho y las capacidades nacionales para combatir la violencia, el terrorismo y otras formas de delincuencia organizada y trasnacional (trata de personas, tráfico drogas y armas), promover los derechos humanos y la igualdad, y en resumen paz, seguridad y desarrollo serían los objetivos a conseguir.

\section{Política criminal y seguridad}

El art. $10^{5}$ de nuestra Carta Magna nos define los fundamentos del orden político y la paz social, requisito sine qua non del modelo de convivencia pacífica y ordenada que pretendemos y que el ODS 16 nos marca. Los fundamentos son la dignidad de la persona, los derechos inviolables que le son inherentes, el libre desarrollo de la personalidad, el respeto a la ley y a los derechos de los demás. En síntesis una sociedad inclusiva que respete los derechos fundamentales.

Habrá paz social y orden político en sociedades seguras, y éstas requieren para la consecución de esta anhelada seguridad, una adecuada política criminal.

Una política es la forma en que el gobierno gestiona los asuntos públicos. La política criminal transforma la

En: https:/www.un.org/sustainabledevelopment/es/peace-justice/ Art. 10.1 CE: "La dignidad de la persona, los derechos inviolables que le son inherentes, el libre desarrollo de la personalidad, el respeto a la ley y a los derechos de los demás son fundamento del orden político y de la paz social." experiencia criminológica en opciones y estrategias asumibles por los poderes públicos con el fin inmediato de la prevención y represión del crimen, amén de la protección y recuperación de sus víctimas.

Siguiendo a FRANZ VON LISZT "La política social se presenta como la mejor y más eficaz política criminal “. Comparto esta opinión, si bien la situación española no ha seguido esta línea.

\subsection{La política criminal en España}

Puede decirse sin ambages que el papel de la política criminal se ha transformado. Por un lado, se ha politizado y se ha vuelto más abierta a la opinión pública; por otro lado, se ha alejado de un tratamiento centrado en la criminalidad y en la persona del delincuente, tratamiento que antiguamente se había conferido a expertos en ciencias penales y criminológicas. La política criminal se ha vuelto por decirlo así más expresiva, más directa, emocional, concibiéndose hoy en día como un instrumento destinado a producir no sólo un mayor sentimiento de seguridad en la población, sino también -por qué negarlo-, a ganar unas elecciones llegado el caso (Caño Paños, 2004).

En lo que se refiere a la política criminal española, asistimos a un proceso permanente de reformas sustantivas, que, en muchos casos, siguen tendencias opuestas, por lo que con toda propiedad puede decirse que se trata de un proceso de reformas y contrarreformas. Un reflejo es que el propio legislador se vea en la obligación de reconocer que uno de los motivos de la principal reforma operada en el CP (2010) son los "efectos de distorsión o incongruencia" generados por "los numerosos y en ocasiones acelerados cambios introducidos en la arquitectura original del texto de 1995" (seguridad vial, drogas o delitos relativos a la propiedad intelectual e industrial son sólo los ejemplos más llamativos de esa política criminal contradictoria $)^{6}$.

La tónica imperante es la de agravar sistemáticamente las penas y crear nuevas figuras típicas. Esa tendencia penalizadora y criminalizadora no parece traer causa de informes criminológicos que aconsejen actuar en tal sentido o, a la inversa, o que acrediten a posteriori que el incremento del rigor penal ha tenido efectos positivos en la reducción de la criminalidad (Cuerda Arnau, 2013). Las reformas penales, a menudo sólo se explican como fruto de la instrumentalización del derecho penal por el propio legislador y por los medios de comunicación. Desde que se aprobó la LO 10/1995, el CP ha sufrido más de veinte reformas. Mientras, todavía estamos a la espera de la imprescindible reforma de nuestro proceso penal. Ambas cosas hablan por sí solas.

\subsection{La política criminal en el ámbito de la seguridad ciudadana y el orden público}

El Grupo de Estudios de Política Criminal (2004), redactaron un manifiesto en la reunión que mantuvieron

Exposición de motivos de la LO 5/2010, de 22 de junio de reforma del CP. 
en Bilbao los pasados 15 y 16 de abril de 2016 en el que reproducían su posición, cuya exposición me parece muy interesante y clarificadora: "1. En las sociedades democráticas el concepto de orden público ha de vincularse necesariamente con el ejercicio de derechos fundamentales y libertades públicas, puesto que la existencia de éstos constituye el presupuesto de la propia organización política. En consecuencia, una nueva política criminal en materia de orden público debería proscribir la tipificación de infracciones penales y administrativas que sancionen el ejercicio legítimo de derechos fundamentales, así como evitar que dicha tipificación, por la vaguedad y amplitud de la redacción o por la desproporción de las sanciones, pueda generar el efecto desaliento que han proscrito el TC y el TEDH. La reforma del Código penal y de la Ley de Seguridad ciudadana de 2015 y las ordenanzas municipales de los últimos años han ampliado las infracciones penales y administrativas que afectan a los usos del espacio público. De esta manera, se reprimen una serie de conductas que antaño fueron consideradas legítimas, algunas incluso propias del ejercicio de derechos fundamentales, con una capacidad expansionista nunca antes vista en la etapa democrática, sorteando las garantías que hemos consensuado desde la configuración del Estado democrático y de derecho. Precisamente en momentos de mayor conflictividad social, como consecuencia de los recortes de los derechos sociales, se han promulgado una serie de normas sancionadoras, penales y administrativas que desincentivan que los ciudadanos ejerzan libertades públicas y parecen no dejar una sola conducta de protesta social sin castigo, al tiempo que desconocen principios básicos del Estado de Derecho como los de legalidad (taxatividad), interdicción de la arbitrariedad, proporcionalidad, culpabilidad, presunción de inocencia y derechos de defensa. El concepto de orden público se convierte así en una noción apta para justificar un poder punitivo expansivo, incierto, con amplia discrecionalidad de las autoridades, consagrando la máxima de esta era neoliberal: un sistema liberal en lo económico, pero altamente intervencionista en lo social. El legislador trasmuta el concepto de orden público a paz pública, privilegiando la autoridad, en un continuo de comportamientos prohibidos, en los que quedan pocos resquicios de libertad. Se trata, por tanto, de una noción de orden público y seguridad ciudadana muy cercana al reconocimiento de la ciudad como un espacio no público, sino de unos pocos. Ello, además, denota un interés político de construir no actores sociales, sino ciudadanos sumisos (muchas infracciones son meras desobediencias) $y$ legitimar la exclusión de sectores problemáticos del espacio público bajo un entendimiento autoritario de la noción de ciudadanía, por lo cual estas normas deben ser reformadas cuanto antes. Una propuesta político criminal alternativa en materia de uso del espacio público debería basarse en la maximización del ejercicio de derechos individuales y en el respeto a los principios fundamentales del ius puniendi. (...)"

Como vemos, sigue la línea de Von Liszt que defiende la política social como mejor política criminal, y más si en lo que a la consecución del ODS 16 se refiere.
Toda nación, entendida como unidad geográfica y política en la que gobierna una específica estructura estatal, en nuestro caso además territorial, necesita establecer propositivamente $\mathrm{y}$ de forma permanente vías y métodos que esgrimirá en su enfrentamiento al fenómeno delictivo (González y Pérez, 2016). De este modo, la política criminal puede ser interpretada como la reacción socio-estatal organizada frente al delito. En tal sentido, se hace útil servirse de los medios, formas, organismos, estructuras, etc., que conciben y aplican dicha Política Criminal. Si vinculamos el término Política Criminal solo a planteamientos y valoraciones de Derecho Penal formaremos una visión jurídica sectorizada y predefinida por el contenido y marco de acción de la justicia penal ${ }^{7}$.

Bustos Ramírez (1996), autor que sustenta una visión amplia de la categoría en estudio, asegura que "política criminal es poder de definir los procesos criminales dentro de la sociedad y, por tanto, de dirigir y organizar el sistema social en relación a la cuestión criminal".

Una perspectiva integral de la política criminal supone emplear el concepto como la reacción socio-estatal ante la criminalidad, como las diversas formas de respuesta que desarrolla el Estado y la Sociedad Civil contra el fenómeno delictivo.

La política criminal desde una perspectiva criminológica tiene un sentido mucho más amplio: incluye las políticas jurídico-penales pero también otras políticas sociales que tienen relevancia para la prevención y la intervención en el fenómeno delictivo (Barberet Havican, 1999).

Los principios básicos de la política criminal procuran garantizar, de un lado, transformaciones estructurales anticriminógenas de efecto general (Política Social) y de otro, tratarán de garantizar correctivos resocializadores de cuestionados y limitados resultados personalizados (política penal).

De este modo y en conclusión, la política criminal más efectiva será siempre la que prevenga el suceso delictivo. El establecimiento de sinergias entre distintas ciencias como el derecho penal y la sociología podrían suponer la eliminación o neutralización de las causas básicas del delito y contribuir de forma muy efectiva y eficiente a la seguridad.

De la Cruz Ochoa (2001: 22-23) expresa que "ciertamente existen medios tanto o más eficaces que la pena. En primer lugar, una política social dirigida a disminuir las diferencias sociales existentes y que vaya modificando el sistema social (...). La mayoría de la delincuencia en todas partes del mundo proviene de las capas más desfavorecidas, quién no desee tener que castigar la pobreza ha de esforzarse, pues, en eliminarla progresivamente mediante una Política Social auténticamente democrática. Esta es la respuesta fundamental que una democracia

Sobre la diversidad de enfoques de estudio de la Política Criminal, vid. Cid Moliné, J. y Larrauri Pijoan, E., Teorías criminológicas. Editorial Bosch, S. A. 2001. Barcelona, pp. 29-31 y especialmente la nota 35 ; Betistain Ipiña, A., Hoy y mañana de la política criminal protectora y promotora de los valores humanos. (La paz desde la victimología). En: Cuadernos de Derecho Judicial. Volumen IX, Política Criminal comparada, hoy y mañana. Editado por el Consejo General del Poder Judicial. 1998. Madrid, pp. 3-19. 
debe dar al crecimiento del delito, y no la de quienes piden que la democracia venga a apretar los resortes de la represión penal para devolver la seguridad ciudadana". Aquí vemos el importante papel que en su caso jugaría también el ODS, fin de la pobreza, y su íntima relación que sostiene también con la seguridad ciudadana.

En síntesis, la vinculación estrecha de la política social y la política penal conforma la política criminal entendida como la estrategia socio-estatal para la prevención del comportamiento delictivo.

La política criminal debe responder a la necesidad de seguridad en sociedades complejas, abiertas y pluralistas: Al tratar de perfilar una estrategia político-criminal aceptable en materia de protección de la seguridad nos surge un primer escollo y es la contraposición entre seguridad y libertad, y aquí entraría el principio constitucional de proporcionalidad, no olvidando que el ámbito de intervención del derecho penal, conforme a sus principios básicos, ha de ser la última ratio.

Paredes Castañón (2006: 132) sostiene que "la política criminal liberal se compromete con el objetivo político de la seguridad en otro sentido, cuando apuesta por emplear intensamente (en el mejor de los casos, pero no siempre, con limites extrínsecos: en los derechos) el poder represivo - no solo el del Estado- para reducir al mínimo que sea posible el número y entidad de las infracciones que afectan a los bienes jurídicos. Así, al lado de una política legislativa penal restrictiva (sobre la base de la exigencia de lesividad) pueden coexistir una política policial, una política penológica y una política penitenciaria extremadamente represivas, extremadamente intervencionistas en la esfera de la libertad individual: pero, eso sí, solo de determinados grupos y clases de individuos, los peligrosos (aquellos que, precisamente, son considerados incapaces de controlarse suficientemente a sí mismos y de aceptar suficientemente el control externo por parte de los poderes sociales)".

Por tanto, en el modelo de política criminal que propongo, creo que deberían abordarse y cohesionarse estas cuestiones. No debemos perder de vista el principio constitucional de proporcionalidad y que verdaderamente el derecho penal sea la última ratio, respetar el principio de intervención mínima es decir, intervenir en los ataques más graves a los bienes jurídicos (lo cual no plantea ninguna duda en el caso de la delincuencia organizada o transnacional, pues nadie cuestiona que el terrorismo y la trata de personas son flagrantes ataques a los derechos humanos y el tráfico de drogas o de armas supone igualmente un impacto en los mismos) y abogamos un enfoque en la política criminal tanto social como penal. El fundamental hincapié lo deberemos hacer en la prevención del delito, y aquí abogamos fundamentalmente por el monitoreo de datos, cuestión a la que me dedicaré con posterioridad, y que recoge la parte sociológica anteriormente apuntada. Apostamos por un modelo policial de protección de la seguridad para la prevención del delito, evitando por tanto mediante su intervención estas conductas, reduciendo en cuanto sea posible el número de las conductas típicas efectivamente realizadas: minimización de la probabilidad de comisión de infracciones penales, lo que no quiere decir una ac- tuación policial que restrinja derechos fundamentales si no que la acción policial preventiva se base en un acopio de información (persona, historia, lugares) almacenada conforme a la legislación protectora de la intimidad (es decir, dotar de importancia y medios a la inteligencia policial) unido a la presencia policial en determinados lugares con la intención de desincentivar la comisión de delitos: una actuación policial más proactiva en la prevención del delito. Un derecho penal proporcional, que proteja los ataques a los derechos fundamentales de la ciudadanía con una política penitenciaria adecuada, enfocada a los fines constitucionales: la reinserción social, que responderán a la prevención general y especial del delito, así como así mismo servirán a la postre a la prevención de otros futuros delitos, dotando de la importancia que requiere la ejecución de penas: no olvidemos los fines preventivo especiales que suponen. El efecto resocializador cobra máxima importancia en la delincuencia organizada y trasnacional.

También resulta de suma importancia por su incidencia en la seguridad el factor territorial del delito.

\subsection{La relevancia del factor territorial del delito}

La participación de las entidades territoriales en la gestión de la seguridad pública tiene incidencia precisamente en la consecución de esta seguridad pública.

Cada vez son más las ciudades a lo largo del mundo que han puesto en marcha diferentes programas gestados en el entorno local y dirigidos a la prevención de la delincuencia, iniciativas que, partiendo desde diversas posiciones ideológicas o técnicas, buscan mejorar las condiciones de vida en los espacios urbanos que ocupan sus habitantes (Ruiz Rodríguez, 2010).

Los entes municipales se sitúan como gestores directos de la política criminal en su territorio y no como simples colaboradores de las instituciones puramente penales. Prueba de ello es el desarrollo de programas $\mathrm{y}$ actuaciones que, relacionadas con la criminalidad a nivel local, que surgen como una necesidad para resolver problemas concretos que alcanzan cierta notoriedad, real o mediática.

Con el ánimo de garantizar la seguridad ciudadana, los ayuntamientos utilizan medios propios que van desde los servicios sociales de protección hasta las policías locales, actuando estas como verdaderas policías de intervención frente al delito partiendo de la ventaja que conlleva el principio de policía de proximidad.

La respuesta preventiva contra la seguridad urbana en los países anglosajones difiere de forma importante de la llevada en otros países continentales europeos, si bien podemos observar actualmente la convivencia en el tiempo y en el espacio de programas municipales que rinden tributo tanto a un modelo preventivo. Observamos a menudo en la gestión de la seguridad de las grandes ciudades ambiciosos programas de protección de las víctimas, más próximos a la prevención situacional, con programas de actuación educativa con jóvenes en riesgo de delinquir, derivados de las teorías de la prevención social, lo cual está redundando de forma satisfactoria en la seguridad ciudadana. 
Por tanto, es acertado contemplar el enfoque territorial en la política criminal, y en este cauce más cercano implicar a la ciudadanía en la prevención del delito.

\section{Delincuencia organizada y transnacional y seguridad. Política criminal}

La criminalidad organizada transnacional desafía la seguridad de todos los países democráticos. Se trata de una forma de criminalidad que requiere del estudio de equipos de investigación interdisciplinares, interprofesionales, e internacionales para alcanzar a desarrollar propuestas significativas y capaces para hacer frente con profesionalidad y eficacia a este flagelo mundial.

Las organizaciones multicriminales supraestatales que operan en el seno de redes internacionales de delincuencia, abarcan un repertorio de actividades que incluyen un inventario muy amplio de delitos, todos ellos con una finalidad fundamentalmente económica. La tendencia a la diversificación y la conexión entre mercados delictuales, obedece al afán de maximización del lucro obtenible.

Es incuestionable que este tipo de delincuencia supone en muchos de los casos -especialmente en el terrorismo y la trata de personas- un flagrante ataque a los derechos fundamentales de las personas, ataque de forma directa, mientras que en otra forma indirecta también suponen un ataque a los derechos humanos otras formas de delincuencia organizada -la corrupción, el tráfico de drogas y armas, el cibercrimen, el blanqueo de capitales- formas en las que los delincuentes están dispuestos a servirse de personas como instrumentos para la persecución de sus fines delictivos (con motivación fundamentalmente lucrativa), despojando de dignidad humana y otros derechos a todas las personas que se puedan interponer en el camino de su actuación. En estos casos es incuestionable su punición dentro del ámbito del derecho penal y el abordaje de una política criminal que ahonde en el derecho penal, pero sería un error olvidar un aspecto de gran incidencia a este respecto: la sociología como herramienta para la prevención del delito.

El monitoreo de datos se hace altamente necesario en este tipo de delincuencia, que nos permitirá adoptar una política criminal adecuada, por lo que los estados deben prestar especial atención a este respecto.

Un ejemplo a este respecto puede ser la política criminal española en la lucha contra la trata de personas.

Para poder desarrollar un análisis cuantitativo de la cuestión en nuestro país, disponemos de los datos ofrecidos por la Unidad de Extranjería de la Fiscalía General del Estado, el Centro de Inteligencia de Terrorismo y Crimen Organizado, (en adelante CITCO), y por la Delegación de Gobierno Para la Violencia de Género, instituciones que emiten un informe con carácter anual. Los datos suministrados por la fiscalía atienden a las Diligencias de Seguimiento por el delito de Trata de Seres Humanos que en un año determinado se siguen en su unidad, y estas diligencias tienen su base en los atestados incoados por Guardia Civil, Policía Nacional, policías autonómicas y diligencias de investigación de los fiscales delegados de extranjería. Es preciso aclarar que la incoación de Diligencias de Seguimiento por la Unidad de Extranjería se produce cuando los fiscales valoran que concurren suficientes indicios de la comisión de conductas tipificadas en el artículo 177 bis del Código Penal. El CITCO analiza las cifras a partir de los datos que le proporcionan las Fuerzas y Cuerpos de seguridad del Estado producto de sus investigaciones penales y administrativas, proporcionando los datos que según la actividad policial se ha considerado que hay indicios de criminalidad por un delito de Trata de Seres Humanos. Por su parte de la Delegación de Gobierno para la Violencia de Género, emite un boletín estadístico anual, que contiene un apartado sobre la lucha contra la trata de mujeres y niñas con fines de explotación sexual, donde señala en su metodología que obtienen sus datos de tres fuentes: En primer lugar figuran datos recogidos por la Delegación del Gobierno para la Violencia de Género, relativos a la asistencia proporcionada a mujeres y niñas víctimas de trata con fines de explotación sexual, a partir de los cuestionarios remitidos a la Delegación del Gobierno para la Violencia de Género por entidades encargadas de proporcionar asistencia a las víctimas de trata con fines de explotación sexual ${ }^{8}$. En segundo lugar, se incluye información procedente del Centro de Inteligencia Contra el Terrorismo y el Crimen Organizado (Ministerio del Interior) sobre prevención y lucha contra la trata de seres humanos con fines de explotación sexual y la explotación sexual, y por último, se presentan datos proporcionados por el Fiscal de Sala de Extranjería de la Fiscalía General del Estado en relación al delito de trata con fines de explotación sexual. Como se ha comentado, todos estos informes son anuales y suelen publicarse a finales del año siguiente.

Estos datos nos ofrecen información sobre los victimarios, segregados por sexo, nacionalidad, la existencia de organización criminal y su modus operandi, así como información de las víctimas, segregados igualmente por géneros, nacionalidades, y con referencia a su vulnerabilidad. Esto nos ofrece valiosos datos de los que nutrir a la inteligencia policial -tan útil en la prevención y persecución de estas modalidades delictivas- y el conocimiento de información para adoptar adecuadas políticas criminales tanto en países de origen como de destino, políticas basadas en la prevención y no sólo (pero también) en la persecución, y obviamente todo esto en sistemas victimocéntricos que no pierdan de vista la protección de las víctimas. Aquí hemos hallado otros pilares en la política criminal en delincuencia organizada y transnacional: la cooperación interinstitucional y la cooperación internacional.

La cooperación interinstitucional en la trata de personas se ha tratado en nuestro país encontrando un reflejo

\footnotetext{
La información proporcionada por las entidades beneficiarias de las subvenciones se refiere a la atención global prestada a víctimas de trata con fines de explotación sexual y a potenciales víctimas, no únicamente a la asistencia proporcionada con la financiación de la DGVG. No obstante, estas entidades no constituyen la totalidad de las que en España pueden ser susceptibles de atender a una víctima de trata, si bien conforman el grupo de entidades más significativo en la materia, por lo que la información proporcionada muestra con bastante rigor la situación real existente.
} 
en el protocolo marco de trata, del año 2011, firmado por los Ministerios de Justicia, de Interior, entonces de Empleo y Seguridad Social, el entonces de Sanidad, Servicios Sociales e Igualdad, la Fiscalía General del Estado y el Consejo General del Poder Judicial: un abordaje y enfoque multidisciplinar que coordina a todos los operadores jurídicos y sociales que intervienen en la lucha contra este flagelo a los derechos humanos.

La cooperación internacional es auspiciada desde UNODC, pues no olvidemos que fue en el seno de Naciones Unidas cuando se firmó la Convención de Delincuencia Organizada y Transnacional ${ }^{9}$, en cuyos anexos se encuentra el Protocolo de Palermo de Palermo. Dentro del ámbito de la Unión Europea, se firma el Convenio de Varsovia ${ }^{10}$. Instrumentos sumamente útiles y necesarios en la delincuencia organizada y transnacional que coordina esfuerzos en la lucha contra este fenómeno delictivo, y todo ello sin perjuicio de otros instrumentos internacionales regionales o bilaterales que lleven a cabo los estados.

A ello se ha de sumar mecanismos eficaces de cooperación judicial y policial, y la importancia de estas instituciones, mediante la formación adecuada de sus operadores, lo que redunda en el ODS 16, instituciones sólidas y por ende eficaces. A modo de ejemplo señalar siguiendo en la trata de personas, la confección por el CGPJ de una guía de criterios de actuación frente a la trata de seres humanos, como herramienta muy útil puesta al servicio de los jueces y juezas, que resume el estado de la cuestión y jurisprudencia del momento. Así mismo es de resaltar la importante actuación de la Unidad de Extranjería de la Fiscalía General del Estado, que reporta todos los datos de los procesos judicializados en España. Así mismo se dictó la instrucción 1/2016 de Secretaría de Estado de Seguridad, sobre actuaciones de las fuerzas y cuerpos de seguridad del estado en la lucha contra la trata de seres humanos y la colaboración con las organizaciones y entidades con experiencia acreditada en la asistencia a víctimas.

Especialmente destacable en el ámbito de la prevención y a tener en cuenta en la política criminal, hemos dicho que juega un papel importante la sociología, y dentro de esta la educación. Me parece un muy buen ejemplo a este respecto la iniciativa de la UNODC en el seno de la Declaración de Doha ${ }^{11}$, que pretende promover una cultura de la legalidad, "Educación para la justicia" que apunta por prevenir la delincuencia y promover una cultura de la legalidad a través de herramientas y recursos educativos ideados para los distintos niveles de educación, primaria, secundaria y terciaria. Estos recursos ayudan a los educadores a enseñar a las próximas generaciones a entender y abordar mejor los problemas que pueden socavar el estado de derecho: involucrar a la ciudadanía en la prevención del delito creando una cultura de la legalidad.

9 Nueva York, 15 de Noviembre de 2000, ratificada por España en 2003 (BOE 29 de septiembre de 2003)

10 Convenio del Consejo de Europa sobre la lucha contra la trata de seres humanos, hecho en Varsovia el 16 de mayo de 2005, ratificado por España en 2009, BOE de 10 de septiembre de 2009.

11 Adoptada en el seno de UNODC en Doha, abril de 2015 sobre la prevención del delito y justicia penal
Por último señalar un intento por el legislador español de adoptar una política criminal contra el crimen organizado y la delincuencia grave es la Estrategia Nacional contra el Crimen Organizado y la Delincuencia Grave, recientemente aprobado (22 de febrero de 2019) $)^{12}$. Es una estrategia nacional que abarca el periodo 2019-2023, donde parte de una visión que dice integral que involucre a todos los operadores jurídicos de la seguridad, tanto exterior como interior de las naciones. Dice partir de principios rectores tales como la unidad de acción, anticipación, eficiencia y resiliencia, pretendiendo ser un elemento de prevención y en la línea de establecer políticas de seguridad pública anticipativas y disuasorias, con la promoción de acciones proactivas y de inteligencia estratégica y operacional. Establece distintos ejes troncales y transversales para dar respuesta global a estos fenómenos delictuales complejos, entre los que se encuentra la prevención a través de la inteligencia, la neutralización de la economía del crimen organizado centrándose en la investigación de la estructura económica, luchando contra los mercados criminales y vinculando el crimen organizado y el terrorismo, pretendiendo la cooperación y coordinación internacional, formación y capacitación de los operadores jurídicos de seguridad. En las líneas de acción concreta las mismas distinguiendo el tipo de delito. Es una herramienta sumamente útil y en la línea de lo que hemos ido marcando en este trabajo, si bien cojea en un punto fundamental de la prevención, y es el involucrar a la ciudadanía en la prevención del delito, creando a través de la educación una cultura de la legalidad que nos aleje del bienestarismo autoritario, lo que es necesario en los modernos estados de derecho, sanos democráticamente hablando y respetuosos con los derechos y libertades de su ciudadanía.

\section{Conclusiones}

Si queremos establecer una adecuada política criminal en la lucha contra la delincuencia organizada y transnacional que redunde en la consecución de la seguridad ciudadana, debemos partir de una perspectiva integral de política criminal, que incluya no solo las políticas jurídico-penales si no también políticas sociales que tengan relevancia en la prevención del delito, estableciendo sinergias entre el derecho penal y la sociología, que tenga en cuenta las actuales sociedades abiertas y plurales. Debemos aprovechar la estructura territorial de nuestro estado para dotar también de un enfoque territorial a la política criminal y aprovechar así el modelo policial español que recoge entre sus fuerzas de seguridad la policía de proximidad. Es importante una adecuada recogida de datos que nos permita monitorear el fenómeno delictivo, conocer victimarios, víctimas, su procedencia, su modus operandi para poder crear una inteligencia policial al servicio de la prevención del delito. La formación y capacitación de todos los operadores que intervienen

12 Orden PCI/161/2019, de 21 de febrero, por la que se Aprueba el Acuerdo del Consejo de Seguridad Nacional, por el que se aprueba la Estrategia Nacional contra el Crimen Organizado y la Delincuencia Grave, BOE de 22 de febrero de 2019. 
en la lucha contra esta delincuencia redunda en una detección precoz de la misma que puede ser otra forma de prevención de futuras comisiones delictivas así como una mejora en la persecución penal de las mismas. Así mismo, constituyen pilares estas políticas la cooperación interinstitucional, a través de protocolos de actuación y fomento de grupos de trabajo con enfoques territorializados, como la cooperación internacional, fomentando las redes policiales, fiscales y judiciales que agilicen y doten de eficiencia la cooperación internacional en la lucha contra esta delincuencia. Todo ello además con la implicación de la ciudadanía en la lucha contra la delincuencia pero no desde un punto de vista represivo, si no utilizando la herramienta más poderosa de la que disponemos para transformar la sociedad: la educación, creando una cultura de legalidad propia de estados de derecho de sociedades democráticamente avanzadas.

Tal vez algunas de estas formas de delincuencia organizada y transnacional precisen de instrumentos normativos más completos para dotar de eficacia su lucha, como sería el caso de la trata de personas. En mi opinión una ley integral contra la trata de personas en la que se aborde en el mismo cuerpo legal la prevención, la perse- cución penal y la protección de víctimas tenga un efecto muy positivo y sea una política criminal muy adecuada, y responda a las necesidades de orden público y paz social evitando el despojo de la dignidad humana que esta conducta supone. Con esto no quiero decir que crea que cada fenómeno delictivo requiera una ley integral propia, pero si en determinados delitos más complejos como puedan ser la trata de personas o el terrorismo.

\author{
Abreviaturas \\ ACNUR: Alto Comisionado de las Naciones Unidas \\ para los Refugiados \\ CE: Constitución Española \\ CGPJ: Consejo General del Poder Judicial \\ CITCO: Centro de Inteligencia de Terrorismo y Cri- \\ men Organizado \\ MGF: Mutilación Genital Femenina \\ ODS: Objetivos de Desarrollo Sostenible \\ CP: Código Penal \\ UNODC: Oficina de las Naciones Unidas Contra la \\ Droga y el Delito
}

\section{Bibliografía}

Barbaret Havican, R. (1999). "La investigación criminológica y la política criminal”, Cuadernos de Derecho Judicial, 5: 221 -244. Beristain Ipiña, A. (1998), "Hoy y mañana de la política criminal protectora y promotora de los valores humanos. (La paz desde la victimología)", Cuadernos de Derecho Judicial, 9: 9-86.

Bustos Ramirez, J. (1996). "Política criminal y Estado", Revista de la Asociación de Ciencias Penales de Costa Rica, 8 (12): 10. Cano Paños, M.A (2004). "La acusación particular en el proceso de menores. ¿La represión como alternativa?, Revista del Poder Judicial, 76: 247-282.

Caid Moliné, J. y Larrauri Pijoan, E. (2001). Teorías criminológicas. Barcelona: Editorial Bosch, S. A.

Cuerda Arnau, M.L (2013). "La expansión del Derecho Penal versus la eficacia del modelo de justicia", Revista Cuadernos Digitales de Formación, 5: 1-15.

De la Cruz Ochoa, R. (2001), "Control social y Derecho Penal”, Revista Cubana de Derecho, 17: 1-20

González Rodríguez, M. y Pérez Nájera, C. (2016). "La política criminal y la seguridad ciudadana en Latinoamérica: Apreciaciones actuales", 3(10): 1-24.

Ruiz Rodríguez, L.R. (2010). "La gestión urbana de la seguridad: política criminal y municipios” en Revista Electrónica de Ciencia Penal y Criminología, 09: 1-25. 